\title{
Zinco, estresse oxidativo e atividade física
}

\author{
Zinc, oxidative stress and physical activity
}

Josely Correa KOURY ${ }^{1}$

Carmen Marino DONANGELO²

\section{R E S U M O}

A atividade física intensa aumenta a formação de espécies reativas de oxigênio que podem causar lesões musculares e danos na membrana de eritrócitos, prejudicando o desempenho de atletas. Para prevenir os efeitos causados pelo estresse oxidativo, o organismo possui vários mecanismos antioxidantes, alguns dependentes de zinco. As propriedades antioxidantes desse mineral são explicadas pelo seu papel na regulação da síntese da metalotioneína, na estrutura da enzima superóxido dismutase e na proteção de agrupamentos sulfidrila de proteínas de membranas celulares por antagonismo com metais pró-oxidantes como ferro e cobre. Estudos têm demonstrado que a fragilidade osmótica de eritrócitos está relacionada à função do zinco na membrana celular. Atletas geralmente apresentam ingestão dietética desse mineral insuficiente para compensar as perdas aumentadas pelo suor e urina e para atender a demanda bioquímica. Este trabalho de revisão visa mostrar a importância biológica e nutricional do zinco na proteção antioxidante durante a atividade física intensa.

Termos de indexação: zinco, atividade física, estresse oxidativo, atleta.

\section{A B S T R A C T}

During intense physical activity there is an increased production of reactive oxygen species that can cause muscle injury and damage to erythrocyte cell membranes, thus impairing athletic performance. In order to prevent the effects caused by oxidative stress, the organism has several antioxidant mechanisms, some of which depending on zinc. The antioxidant properties of this mineral are explained by its role in the regulation

\footnotetext{
1 Universidade Federal do Rio de Janeiro, Instituto de Nutrição, Departamento de Nutrição Básica. R. São Francisco Xavier, 524, $12^{\circ}$ andar, sala 12006-D, 20559-900, Maracanã, Rio de Janeiro, RJ, Brasil. Correspondência para/Correspondence to: J.C. KOURY. E-mail: jckoury@hotmail.com

2 Departamento de Bioquímica, Instituto de Química, Laboratório de Bioquímica Nutricional e de Alimentos, Universidade Federal do Rio de Janeiro.
} 
of metallothionein synthesis, in the structure of superoxide dismutase, and in the protection of sulfhydryl groups of cell membrane proteins through antagonism with pro-oxidant metals such as iron and copper. Recent studies have shown that the osmotic fragility of erythrocytes is related to the zinc function in cell membranes. Athletes generally have dietary zinc intakes inadequate to compensate for the increased sweat and urine losses to meet and the high biochemical demand. This paper reviews the biological and nutritional significance of zinc in the antioxidant protection during intense physical activity.

Index terms: zinc, motor activity, oxidative stress, athlete.

\section{N T R O D U Ç Ã O}

Durante a atividade física ocorrem diversas adaptações fisiológicas, sendo necessários ajustes cardiovasculares e respiratórios para compensar e manter o esforço realizado. O exercício físico intenso induz a formação excessiva de espécies reativas de oxigênio associadas ao metabolismo energético acelerado. Essas espécies podem contribuir para danos tissulares e celulares e prejudicar o desempenho do atleta.

Para prevenir ou reduzir os efeitos causados pelo estresse oxidativo gerado pelo exercício intenso, o organismo está equipado com diversos mecanismos de defesa antioxidante. Nesses mecanismos, vários micronutrientes desempenham papel importante, entre eles o zinco, que participa da estrutura da enzima superóxido dismutase, além de ser um potente estabilizador das membranas celulares, de proteínas estruturais e da sinalização celular ${ }^{1,2}$.

Atualmente muitos pesquisadores têm demonstrado interesse em elucidar a influência de micronutrientes sobre o estresse oxidativo na atividade física, com o intuito de minimizar os efeitos prejudiciais do excesso de espécies reativas de oxigênio e melhorar a capacidade antioxidante dos atletas através da adequação do estado nutricional em micronutrientes ${ }^{1-3}$. Este trabalho de revisão tem por objetivo destacar a importância biológica e nutricional do zinco na redução e/ou prevenção dos efeitos do estresse oxidativo promovido pelo exercício físico intenso.

\section{Exercício físico como agente pró-oxidante}

As espécies reativas de oxigênio são átomos, íons ou moléculas que contêm oxigênio com um elétron não pareado em sua órbita externa. São caracterizadas por grande instabilidade e por isso elevada reatividade, e tendem a ligar o elétron não pareado com outros presentes em estruturas próximas de sua formação, comportando-se como receptores (oxidantes) ou como doadores (redutores) de elétrons. As espécies reativas de oxigênio são constantemente formadas no organismo humano, tal como ocorre, por exemplo, durante a fagocitose realizada pelos neutrófilos, monócitos e macrófagos, no combate a microorganismos invasores ${ }^{4}$ (Quadro 1).

Existem espécies reativas de oxigênio muito prejudiciais, tais como o radical hidroxila $(\bullet \mathrm{OH})$, que reagem indiscriminadamente com a maioria dos compostos orgânicos essenciais à integridade e função dos organismos vivos - as biomoléculas, exercendo efeitos biológicos prejudiciais ${ }^{5}$. Os radicais livres podem atacar todas as principais classes de biomoléculas, sendo os lipídeos os mais suscetíveis. Os ácidos graxos poliinsaturados (PUFA) das membranas celulares

Quadro 1. Redução do oxigênio a espécies reativas.

\begin{tabular}{ll}
\hline $\mathrm{O}_{2}+\mathrm{e}^{-} \rightarrow \mathrm{O}_{2}^{-} \bullet$ & radical superóxido \\
$\mathrm{O}_{2}^{-} \bullet+\mathrm{H}_{2} \mathrm{O} \rightarrow \mathrm{HO}_{2}^{-} \bullet+\mathrm{OH}$ & radical hidroperoxil \\
$\mathrm{HO}_{2}^{-} \bullet+\mathrm{e}^{-}+\mathrm{H} \rightarrow \mathrm{H}_{2} \mathrm{O}_{2}$ & peróxido de hidrogênio \\
$\mathrm{H}_{2} \mathrm{O}_{2}+\mathrm{e}^{-} \rightarrow \bullet \mathrm{OH}+\mathrm{OH}^{-}$ & radical hidroxila \\
\hline
\end{tabular}


são rapidamente atacados por radicais oxidantes. A destruição oxidativa dos PUFA, conhecida como peroxidação lipídica, é bastante lesiva por ser uma reação de auto-propagação na membrana ${ }^{4}$.

$\mathrm{Na}$ atividade física intensa há um aumento de 10 a 20 vezes no consumo total de oxigênio do organismo e um aumento de 100 a 200 vezes na captação de oxigênio pelo tecido muscular ${ }^{4}$, favorecendo o aumento da produção de espécies reativas de oxigênio. As modalidades esportivas que obtêm energia através do metabolismo aeróbio apresentam, portanto, mais facilidade de promover a liberação dessas substâncias em comparação com aquelas que obtêm energia através do metabolismo anaeróbio. Com isso os atletas ligados a modalidades aeróbias sofrem mais as conseqüências da presença de espécies reativas de oxigênio².

O exercício físico intenso pode ativar três principais vias de formação de espécies reativas de oxigênio: produção mitocondrial, produção citoplasmática e produção favorecida pelos íons ferro e cobre.

\section{Produção mitocondrial de espécies reativas de oxigênio}

Nos organismos aeróbios, o oxigênio consumido é reduzido a água na mitocôndria. A enzima catalisadora desta reação é a citocromo oxidase a qual impede a produção elevada de espécies reativas de oxigênio nas mitocôndrias das células. No entanto, de $2 \%$ a $5 \%$ do oxigênio consumido pelos organismos gera normalmente espécies reativas de oxigênio nestas organelas com a formação do íon superóxido e de peróxido de hidrogênio ${ }^{4}$.

Várias evidências indicam que ocorre elevação na produção mitocondrial de espécies reativas de oxigênio no organismo durante o exercício físico. Uma delas é o aumento de duas a quatro vezes na atividade das enzimas reguladoras (citrato sintetase, isocitrato desidrogenase e oxoglutarato desidrogenase) do Ciclo de Krebs no músculo esquelético, como conseqüência do exercício físico e treinamento de resistência aeróbia. A elevação acentuada da atividade destas enzimas é consistente com o metabolismo mitocondrial ativado nesta situação ${ }^{5}$.

\section{Produção citoplasmática de espécies reativas de oxigênio}

Durante o exercício físico intenso ocorre elevação da atividade do ciclo de degradação das purinas. Neste ciclo, a adenosina monofosfato (AMP) é desaminada pela enzima adenilato desaminase, a inosina monofosfato (IMP) que se acumula no músculo esquelético. Como a IMP não se difunde rapidamente do músculo esquelético durante o exercício intenso, o seu acúmulo pode levá-la a uma via secundária de metabolização, ocasionando a formação de hipoxantina, xantina, ácido úrico, oxi-radicais e peróxido de hidrogênio, produtos finais da degradação de adeninas ${ }^{6}$.

$\mathrm{Na}$ presença de oxigênio molecular, a enzima xantina oxidase catalisa a oxidação da hipoxantina a xantina e esta à ácido úrico. Em condições de repouso, esta enzima está na forma de xantina desidrogenase (pouco ativa), utilizando o NAD+ como aceptor de elétrons. Quando há isquemia provocada pelo exercício intenso, essa enzima é convertida à forma oxidase usando o oxigênio molecular como aceptor de elétrons, gerando com isso íon superóxido e peróxido de hidrogênio ${ }^{6}$.

\section{Produção de espécies reativas de oxigênio favorecida pelos íons ferro e cobre}

O ferro e o cobre são transportados, utilizados e estocados ligados a proteínas específicas (transferrina, ferritina e ceruloplasmina), as quais previnem ou minimizam as reações de oxidação catalisadas por estes minerais. Os íons ferro e cobre são muito ativos em reações de óxido-redução. 0 
ciclo redox desses minerais promove a reação de Fenton (abaixo), a qual libera um potente radical oxidante - hidroxila $(\cdot \mathrm{OH})$ - a partir do $\mathrm{H}_{2} \mathrm{O}_{2}$. $\mathrm{A}$ $\cdot \mathrm{OH}$ é capaz de retirar um átomo de hidrogênio dos ácidos graxos poliinsaturados da membrana celular e iniciar a peroxidação lipídica. O resultado é o acúmulo de hidroperóxidos que destroem a estrutura e função da membrana?.

Reação de Fenton:

$$
\mathrm{Cu}^{+2} / \mathrm{Fe}^{+2}+\mathrm{H}_{2} \mathrm{O}_{2} \longrightarrow \mathrm{Cu}^{+3} / \mathrm{Fe}^{+3}+\mathrm{OH}^{-}+\cdot \mathrm{OH}
$$

Existem evidências de que no citossol das células hepáticas há "ferro livre" ou "ferro lábil" (não ligado à ferritina), definido como aquele ligado fracamente a compostos de baixo peso molecular. Este ferro é facilmente dissociado na forma de íon, tornando-se cataliticamente ativo e apto a participar das reações de produção de espécies reativas de oxigênio. Essas espécies causam vários prejuízos celulares, inclusive às proteínas reguladoras e/ou limitadoras da captação do ferro extracelular. Como conseqüência do excesso oxidativo, ocorre injúria celular com a possível destruição da membrana e morte celular?

Existem fatores durante a atividade física intensa, tais como a acidose metabólica, que podem liberar ferro da hemoglobina (ou da mioglobina), tornando-o disponível para participar da formação do radical ' $\mathrm{OH}$ intracelular'. Nos eritrócitos, esta liberação é acompanhada pela formação de metahemoglobina, principalmente quando os mesmos estão depletados de glutatião reduzido. A liberação do ferro é acompanhada pela peroxidação lipídica da membrana e como conseqüência ocorre hemólise ${ }^{8}$.

\section{Sistema de defesa antioxidante}

O sistema de defesa antioxidante do organismo tem como principal função inibir ou reduzir os danos causados às células pelas espécies reativas de oxigênio. Existe uma grande variedade de substâncias antioxidantes, as quais podem ser classificadas em função da origem e/ou localização em antioxidantes dietéticos e antioxidantes intra e extracelulares ${ }^{9}$. O mecanismo de ação dos antioxidantes permite ainda classificá-los como antioxidantes de prevenção (impedem a formação de radicais livres), varredores (impedem o ataque de radicais livres às células) e de reparo (favorecem a remoção de danos da molécula de DNA e a reconstituição das membranas celulares danificadas) ${ }^{9}, 10$ (Quadro 2).

O desequilíbrio entre a liberação de espécies reativas de oxigênio e a capacidade de ação dos sistemas de defesa antioxidante promove o estresse oxidativo. 0 excesso de liberação de espécies reativas de oxigênio faz parte do mecanismo intermediário de várias doenças que

Quadro 2. Principais substâncias antioxidantes.

\begin{tabular}{lll}
\hline Antioxidantes Dietéticos & Antioxidantes Extracelulares & Antioxidantes Intracelulares \\
\hline Prevenção & Prevenção & Prevenção \\
Zinco & Albumina & Glutationa peroxidase \\
Selênio & Bilirrubina & Superóxido dismutase (zinco) \\
& Ceruloplasmina & Ácido Úrico \\
Varredores & Ferritina & Coenzima Q \\
Ácido ascórbico & Mioglobina & Catalases \\
Alfa-tocoferol & Metalotioneína (zinco) & Reparo \\
Carotenóides & Haptoglobina & Metaloenzimas (zinco) \\
& Varredores & Varredores \\
& Ácido ascórbico & Ácido ascórbico \\
& Alfa-tocoferol & Alfa-tocoferol \\
& Carotenóides & Carotenóides \\
\hline
\end{tabular}


envolvem isquemia, inflamação, trauma, doenças degenerativas e morte celular por ruptura da membrana (lipoperoxidação) e inativação enzimática ${ }^{10}$.

\section{Papel biológico do zinco}

O zinco desenvolve várias funções no organismo, explicadas em parte pelo papel catalítico e/ou estrutural em mais de 200 enzimas e pela sua ação na estabilização de domínios de proteínas que interagem com DNA ou de proteínas com papel estrutural ou de sinalização"11 (Quadro 3).

Quadro 3. Funções do zinco no organismo.

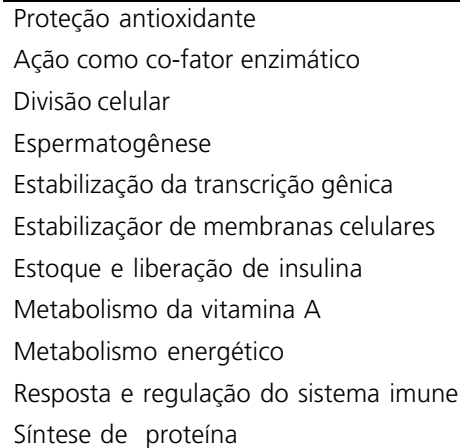

A participação do zinco no sistema de proteção antioxidante é evidenciada por meio de estudos in vivo, os quais demostram que a deficiência de zinco provoca lesões oxidativas relacionadas à ação de espécies reativas de oxigênio em animais e em humanos, e por meio de estudos in vitro, os quais demostram o antagonismo do zinco à formação de radicais livres em modelos bioquímicos e celulares ${ }^{12}$.

O papel exato do zinco como antioxidante não foi ainda elucidado, mas as evidências disponíveis indicam ação desse mineral envolvendo vários mecanismos ${ }^{12,13}$. Esses mecanismos incluem a regulação da expressão de metalotioneína, a atividade da enzima superóxido dismutase e a proteção de grupamentos sulfidrila de proteínas de membranas celulares por antagonismo com metais pró-oxidantes como cobre e ferro. A ação antioxidante desse mineral é indireta, uma vez que o íon zinco não é ativo em reações de óxidoredução.

O zinco induz a síntese da metalotioneína (MT), família de proteínas de baixo peso molecular (6000-7000 kDa), rica em resíduos de cisteína (25\%-30\%), porém sem ligações dissulfeto e com capacidade de ligação de 5-7 átomos de Zn por molécula. A MT apresenta propriedades antioxidantes em uma diversidade de condições tais como exposição à radiação, drogas e metais pesados ${ }^{12-14}$. A MT inibe reações de propagação de radicais livres através da ligação seletiva de íons de metais pró-oxidantes como ferro e cobre, e dos potencialmente tóxicos como cádmio e mercúrio ${ }^{14}$. Recentemente, tem sido levantada a hipótese de que a regulação da síntese de MT é o nexo entre o estado nutricional em zinco e o estado redox das células. Sob condições de elevado estresse oxidativo, haveria liberação do zinco ligado à $M T$, resultando em maior disponibilidade de agrupamentos sulfidrilas reduzidos da MT prontos para atuar na proteção antioxidante. Por sua vez, o zinco liberado seria redistribuído na célula, podendo ser utilizado em outros mecanismos de proteção antioxidante. A capacidade de regulação da síntese de MT depende de um estado nutricional adequado de zinco ${ }^{13}$.

O zinco é componente estrutural e catalítico da enzima superóxido dismutase (SOD) presente no citoplasma de todas as células, que possui como centro ativo um íon cobre e um íon zinco $^{5}$. Esse mineral também compõe a enzima superóxido dismutase extracelular (EC-SOD), presente no plasma, na linfa e no fluido sinovia|20. A ação da SOD é catalisar a conversão de dois radicais íon superóxido a peróxido de hidrogênio e oxigênio molecular, como mostra a reação:

$$
\mathrm{O}_{2}^{-\cdot}+\mathrm{O}_{2}^{-\cdot}+2 \mathrm{H}^{+} \longrightarrow \mathrm{H}_{2} \mathrm{O}_{2}+\mathrm{O}_{2}
$$

A ação dessa enzima reduz a toxicidade das espécies reativas de oxigênio, transformando uma espécie altamente reativa (radical íon superóxido) em uma forma menos danosa às 
células (peróxido de hidrogênio). Enquanto a SOD citoplasmática parece apenas dependente do estado nutricional em cobre do organismo, tem sido demonstrado que a atividade da EC-SOD é reduzida na deficiência de zinco ${ }^{15}$.

O zinco é essencial para a integridade e funcionalidade das membranas celulares. A sua concentração na membrana das células pode ser bastante elevada dependendo do tipo celular e é influenciada pelo estado nutricional em zinco do organismo. Tem sido demonstrado que a sua deficiência aumenta a fragilidade da membrana de eritrócitos em ratos e em humanos ${ }^{16-18}$. O aumento de fragilidade osmótica de eritrócitos na deficiência de zinco tem sido associado a menor disponibilidade de grupamentos $\mathrm{SH}$ reduzidos na membrana ${ }^{17}$. Conforme relataram Bettger \& $\mathrm{O}^{\prime}$ Dell ${ }^{16}$, em eritrócitos de ratos deficientes em zinco ocorre a perda do mineral da membrana mas não do zinco intracelular. Estes pesquisadores sugerem que a perda de zinco da membrana celular é um dos primeiros sinais de depleção deste mineral no organismo. Esta perda pode afetar a função da membrana celular, alterando a fluidez, os canais de transporte de sódio e de cálcio e o balanço hídrico e osmótico da célula. A participação do zinco na estabilidade de membranas tem sido explicada pelos seguintes mecanismos: 1) promove a associação entre as proteínas de membrana e as do citoesqueleto; 2 ) estabiliza a forma reduzida de grupamentos sulfidrilas, contribuindo para a proteção antioxidante contra os efeitos de ruptura de membranas causados por oxidação de lipídios e proteínas; e 3) preserva a integridade de canais iônicos, agindo assim como antagonista ao efeito adverso do íon $\mathrm{Ca}^{+2}$ livre ${ }^{16,19}$

\section{Estado nutricional de zinco e desempenho de atletas}

O estado nutricional de zinco é de difícil avaliação, uma vez que ainda não foram identificados indicadores bioquímicos bastante sensíveis ${ }^{19}$. Zinco plasmático (ou sérico) é o indicador mais utilizado. Os níveis de zinco plasmático em atletas dependem de vários fatores tais como tipo, intensidade e duração do exercício. Alguns estudos têm demonstrado estado de hipozincemia (zinco sérico $<75 \mu \mathrm{g} / \mathrm{dL}$ ) em atle$\operatorname{tas}^{20}$. No entanto, outras pesquisas encontraram zinco sérico em concentração normal ou elevada em atletas com predomínio de atividade anaeróbia, como judocas ${ }^{21,22}$.

Resultados da concentração de zinco no soro ou plasma obtidos logo após o exercício físico têm de ser avaliados com cautela, pois nos primeiros 30 minutos após exercício de resistência têm sido observados tanto reduções (12\%-33\%) quanto aumentos significativos de concentração de zinco, neste último caso seguido de rápido declínio. Redução do zinco sérico tem sido também observada no período de 2 a 24 horas após corrida de longa distância ${ }^{20,23}$.

A hipozincemia em atletas pode ser causada pela ingestão inadequada de zinco, pela expansão do volume plasmático resultando em hemodiluição, pelo aumento das perdas de zinco através de suor e urina e pela redistribuição de zinco plasmático para o fígado e/ou eritrócitos após o exercício ${ }^{3}$. Níveis aumentados de interleucinas plasmáticas, tal como ocorrem na inflamação, no dano tissular e também no exercício intenso, estimulam o fígado a aumentar a captação do zinco do plasma para a síntese de metalotioneína (e possivelmente de superóxido dismutase e outras zinco-proteínas), necessária aos mecanismos de resposta aguda ${ }^{14}$.

O aumento do zinco sérico em algumas modalidades esportivas logo após o exercício poderia ser também explicado pela mobilização do mineral entre tecidos. O pico de concentração do zinco sérico imediatamente após o exercício intenso tem sido atribuído ao seu rápido extravasamento do tecido muscular danificado para o fluido extracelular ${ }^{24}$. O posterior declínio de concentração do zinco plasmático tem sido explicado pela mobilização de zinco do plasma para o fígado em resposta ao aumento de interleucinas circulantes ${ }^{3}$. 
O exercício físico intenso e as temperaturas extremas são também promotores da perda de micronutrientes do organismo. A perda de minerais pela sudorese durante o treinamento e competição, principalmente quando realizados em elevadas temperaturas, é substancial. O zinco é normalmente perdido do organismo através do intestino (0,5 a 3mg/dia) e da pele (0,5mg/dia), e em esportes aquáticos, dependendo da permanência na água, a perda pela pele pode duplicar. A excreção urinária desse mineral é geralmente baixa $(<0,1 \mathrm{mg} / \mathrm{dia})$, mas essa perda pode aumentar 50\%-60\% em resposta ao exercício prolongado. Em geral, as variações na excreção urinária de zinco em resposta ao exercício refletem as mudanças no turnover do tecido muscular associadas ao exercício ${ }^{3,25}$.

A ingestão recomendada de zinco na dieta é de $8 \mathrm{mg} /$ dia para mulheres e de $11 \mathrm{mg} /$ dia para homens ${ }^{26}$. Não há recomendações específicas para atletas, os quais têm o hábito de consumir dietas ricas em energia, fato que, no entanto, não é garantia do consumo de quantidades adequadas de minerais e vitaminas. Segundo verificaram Van Erp-Baart et al. ${ }^{27}$, em extenso estudo com atletas alemães de diferentes modalidades, aumento de $100 \%$ na ingestão energética estava associado com aumento bem inferior a 100\% no consumo de ferro, cálcio, zinco e vitaminas. Lukaski et al. ${ }^{28}$, estudando nadadores americanos de elite, observaram que a ingestão de zinco (e também de cobre e ferro) era inferior à necessidade diária, apesar de a ingestão energética estar adequada. Em muitas modalidades esportivas, tais como luta, dança e ginástica, há restrição voluntária da ingestão de energia, o que compromete seriamente o consumo adequado de micronutrientes, incluindo o zinco ${ }^{3}$. Em geral, a ingestão marginal ou deficiente desse mineral na dieta é mais freqüente em atletas do gênero feminino do que masculino, pois o consumo de energia é usualmente menor em mulheres e a restrição voluntária de ingestão de energia é também mais freqüente neste grupo. Com ingestão reduzida ou marginal de zinco, o organismo utiliza mecanismos de ajustes para manter a homeostase, tais como alteração na taxa de turnover do zinco plasmático e tissular e na excreção de zinco urinário e fecal, de forma a assegurar a manutenção das funções vitais dependentes desse mineral ${ }^{11}$. Entretanto, o papel do zinco nos mecanismos de proteção antioxidante associados à intensa atividade física pode ficar limitado em virtude da sua baixa ingestão, prejudicando a performance e a saúde do atleta.

Uma forma de compensar a ingestão dietética insuficiente de minerais e vitaminas e com isso minimizar os efeitos das espécies reativas de oxigênio associadas ao exercício físico é o uso de suplementos. Muitos investigadores têm estudado o efeito da suplementação com micronutrientes na redução de indicadores de estresse oxidativo em atletas ${ }^{1,2}$. A suplementação de zinco por atletas tem sido associada com maior força muscular isométrica e maior resistência muscular ${ }^{29}$. No entanto, não há relatos na literatura de possíveis efeitos benéficos dessa suplementação na proteção antioxidante de atletas. Cabe ressaltar que esse consumo suplementar deve ser feito com cautela para evitar possíveis efeitos adversos. A suplementação excessiva de zinco (50 mg/dia) pode inibir a absorção de cobre proveniente da dieta ${ }^{23}$. Além disso, a suplementação de $160 \mathrm{mg}$ de zinco por dia, durante 16 semanas, foi associada à redução da concentração de lipoproteína plasmática de alta densidade (HDL) em homens ${ }^{30}$. O uso de zinco suplementar na faixa de 17 a 50mg/dia é suficiente para reduzir o aumento do colesterol-HDL, induzido pela atividade física ${ }^{23}$.

\section{CONSIDERAÇÕ ES FINAIS}

O zinco é um nutriente com papel biológico essencial nos mecanismos de proteção antioxidante, principalmente nos relacionados às membranas celulares, bastante requisitados durante a atividade física intensa. Os estudos nutricionais demonstram que os atletas geralmente consomem quantidade de zinco na dieta insufi- 
ciente para compensar as perdas aumentadas pelo suor e urina e para atender a elevada demanda bioquímica. Este nutriente merece maior atenção no aconselhamento nutricional para minimizar os danos causados pelo estresse oxidativo sobre o desempenho e a saúde dos atletas.

\section{REFERÊ NCIAS}

1. Clarkson PM, Thompson HS. Antioxidants: what role do they play in physical activity and health? Am J Clin Nutr 2000; 72:637-47.

2. Goldfarb AH. Nutritional antioxidants as therapeutic and preventive modalities in exercise-induced muscle damage. Can J Appl Physiol 1999; 24:249-66

3. Lukaski HC. Magnesium, zinc, and chromium nutriture and physical activity. Am J Clin Nutr 2000; 72:585-93.

4. Halliwell B, Gutteridge JMC. Free radical in biology and medicine. 2nd ed. New York: Oxford University Press; 1989.

5. Lehninger AL, Nelson DL, Cox MM. Príncipios de bioquímica. São Paulo: Savier; 1998. p.41-60.

6. Vina J, Gimeno A, Sastre J, Desco C, Asensi M, Pallardo FV, et al. Mechanism of free radical production in exhaustive exercise in humans and rats; role of xanthine oxidase and protection by allopurinol. IUBMB Life 2000; 49:539-44.

7. Welch KD, Davis TZ, Van Eden ME, Aust SD. Deleterious iron-mediated oxidation of biomolecules. Free Radical Biol Med 2002; 32: 577-83

8. Comporti M, Signori C, Buonocore G, Ciccoli L. Iron release, oxidative stress and erythrocyte ageing. Free Rad Biol Med 2002; 32:568-776.

9. Jacob MJ. The integrated antioxidants systems. Nutr Res 1985; 15:755-65.

10. Strain JJ, Benzie IFF. Antioxidants. In: Encyclopedia of Human Nutrition. New York: Academic Press; 1998. p.95-105.
11. King JC, Shames DM, Woodhouse, L. Zinc homeostasis in humans. J Nutr 2000; 130: 1360s-6S.

12. Powell SR. The antioxidant properties of zinc. J Nutr 2000; 130:1447S-54S.

13. Maret $W$. The function of zinc metallothionein: a link between cellular zinc and redox state. J Nutr 2000; 130:1455S-8S.

14. Hammer DH. Metallothionein. Ann Rev Biochem 1986; 55:913-51.

15. Olin KL, Golub MS, Gershwin ME, Hendricksc AG, Lonnerdal B, Keen CL. Extracellular superoxide dismutase activity is affected by dietary zinc intake in nonhuman primate and rodent models. Am J Clin Nutr 1995; 61:1263-7.

16. Bettger WJ, O'Dell BL. Physiological roles of zinc in the plasma membrane of mammalian cells. J Nutr Biochem 1993; 4:194-207.

17. O'Dell. Role of zinc in plasma membrane function. J Nutr 2000; 130:1432S-6S.

18. Woodhouse LR, Sutherland B, Lederer LJ, Lowe $N M$, King J. The effect of zinc intake on erythrocyte fragility in humans. FASEB J 1998; 12A:1270.

19. Wood, RJ. Assessment of marginal zinc status in humans. J Nutr 2000; 130:1350S-54S.

20. Cordova A, Mon-Alvarez M. Behaviour of zinc in physical exercise: a special reference to immunity and fatigue. Neurosci Biobehav Rev 1995; 19: 439-45.

21. Koury JC, Junior AVO, Portella ES, Oliveira K, Trugo NMF, Donangelo CM. Estudo comparativo de indicadores hematológicos, ingestão de micronutrientes e composição corporal em triatletas e judocas brasileiros de elite. In: Anais do $12^{\circ}$ Congresso Latinoamericano de Nutrición; 2000; Buenos Aires. Buenos Aires: La Sociedad Latinoamericana de Nutrición; 2000. p.28.

22. Singh A. Biochemical indices of selected trace minerals in men: effect of stress. Am J Clin Nutr 1981; 53:126-30.

23. Lukaski HC. Micronutrients ( $\mathrm{Mg}, \mathrm{Zn}, \mathrm{Cu})$ : are mineral supplements needed for athletes? Int J Sports Nutr 1995; 5:574-83. 
24. Mundie TG, Hare B. Effects of resistence exercise, on plasma, erythrocyte, and urine Zn. Biol Trace Elem Res 2001; 79:23-8.

25. Van-Rij AM, Hall MT, Dohm, GL, Bray J, Poires WJ. Changes in zinc metabolism following exercise in human subjects. Biol Trace Elem Res 1986; 10: 99-106.

26. Trumbo P, Yates AA, Schlicker, Poos M. Dietary Reference Intakes: Vitamin A, vitamin K, Arsenic, Boron, Chromium, Copper, Iodine, Iron, Manganese, Molybdenum, Nickel, Silicon, Vanadium and zinc. J Am Diet Assoc 2001; 101:294-301.

27. Van Erp-Baart AMJ, Saris WHN, Binkhorst RA, Vos $J A ́$, Elvers JWH. Nationwide survey on nutritional habits in elite athletes. Part II Mineral and vitamin intake. Int J Sports Med 1989; 10: 511-16.

28. Lukaski HC, Bonita SH, Sandra KG, Bolonchu K. Physical training and copper, iron, and zinc status of swimmers. Am J Clin Nutr 1990; 51:1093-99.

29. Krotkiewski M, Gudmundsson M, Backstrom P, Mandroukas K. Zinc and muscle strength and endurance. Acta Physiol Scand 1982;116:309-11.

30. Hooper PL, Visconti L, Garry PJ, Johnson GE. Zinc lowers high density lipoprotein cholesterol levels. J Am Med Assoc 1980; 244:1960-1.

Recebido para publicação em 20 de maio de 2002 e aceito em 27 de janeiro de2003. 